\title{
Creating a Bimodal Drop-Size Distribution in the NASA Glenn Icing Research Tunnel
}

Laura E. King-Steen - HX5 Sierra LLC

Robert F. Ide - HX5 Sierra LLC

Cleveland, Ohio

AIAA Atmospheric and Space Environments Conference June 9, 2017 


\section{The Problem:}

- The FAA's new Appendix O criteria for super-cooled large drops was put into effect in 2015. One of the biggest problems is no facility has shown the ability to create these conditions.

- Appendix O criteria are difficult to create in ground test facilities because of all the parameters that are difficult to match:

- Large max drop diameter

- Low liquid water content

- Bimodality of drop size distribution

- Trajectories of large drops

- Temperature of large drops

- Velocity of large drops

- Possibility of drop shear

- No experimental facilities also means no validation of icing codes (a)
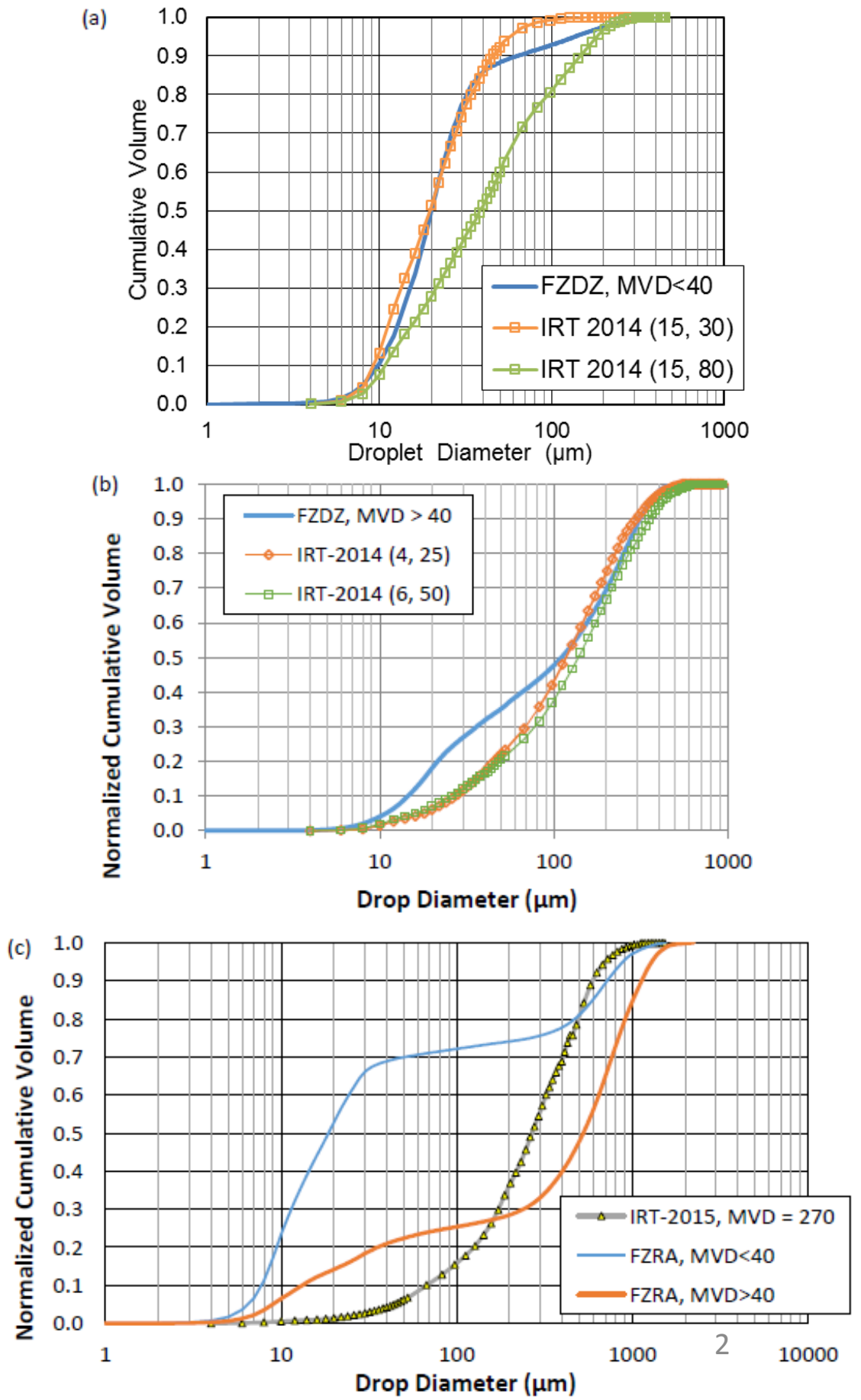


\section{Test Facility}

\section{Icing Research Wind Tunnel}

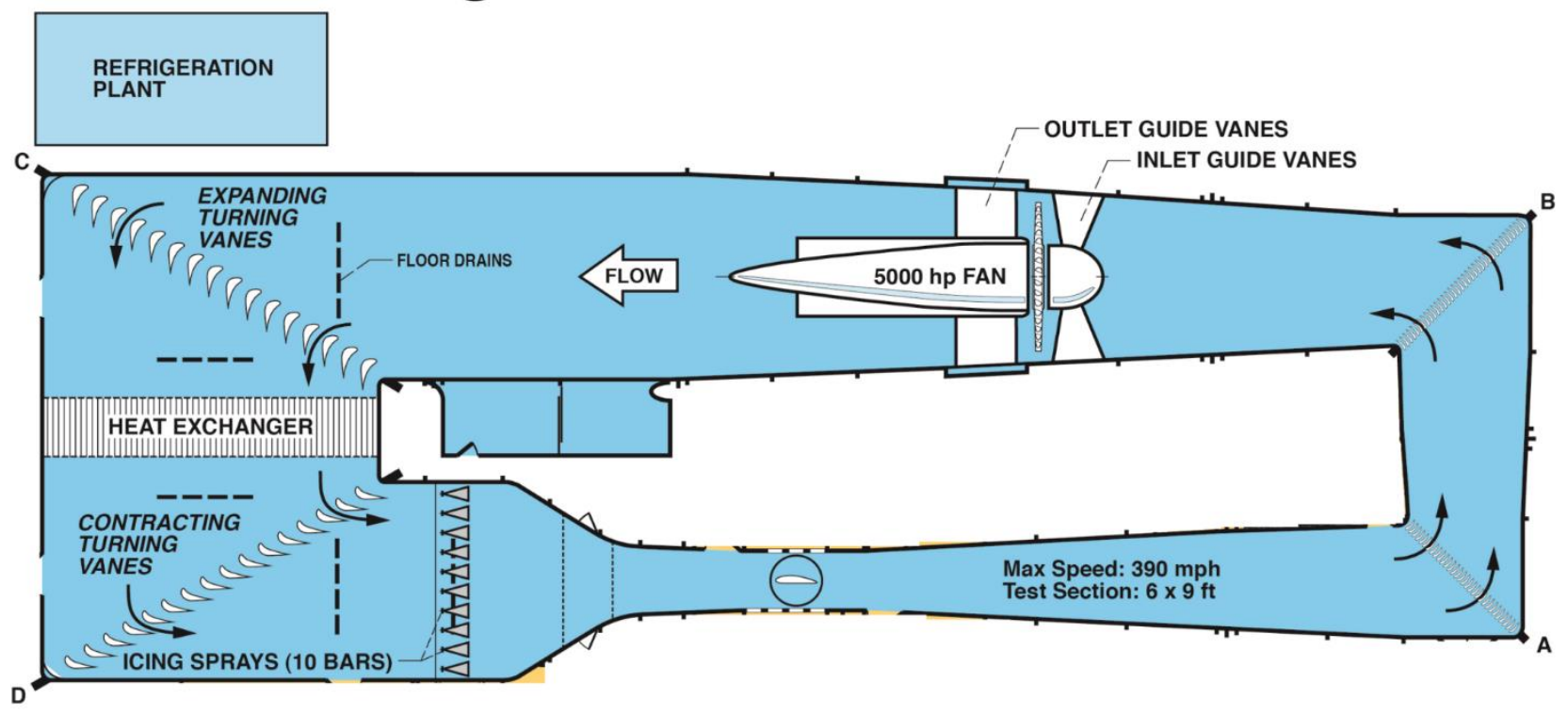

CD-10-83244C

- Test section size: $6 \mathrm{ft}$. $\times 9 \mathrm{ft} .(1.8 \mathrm{~m} \times 2.7 \mathrm{~m})$

- All drop-sizing measurements are made in the center of the test section

- Calibrated test section airspeed range: $50-325$ kts

- Air temperature: $-\mathbf{4 0}$ degC static to $+\mathbf{1 0}$ degC total
- Calibrated MVD range: $14-270 \mu \mathrm{m}$

- Calibrated LWC range: $0.15-4.0 \mathrm{~g} / \mathrm{m}^{3}$ (function of airspeed)

- Two types of spray nozzles:

- Standards = higher water flow rate

- $\operatorname{Mod} 1=$ lower water flow rate 


\section{Drop-Sizing Instruments}

Cloud Droplet Probe (CDP)

$(2-50 \mu \mathrm{m})$ (Forward Scattering)

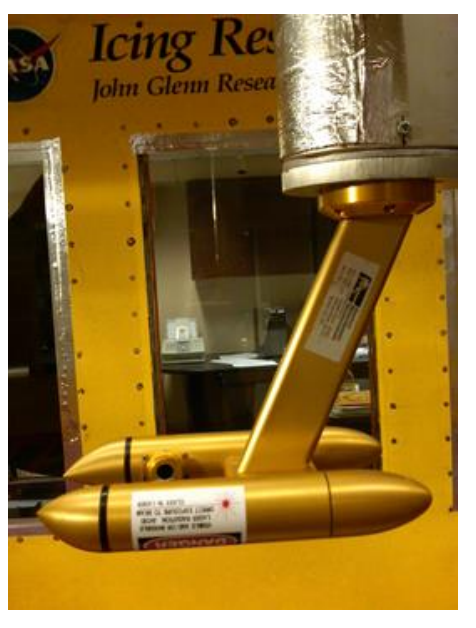

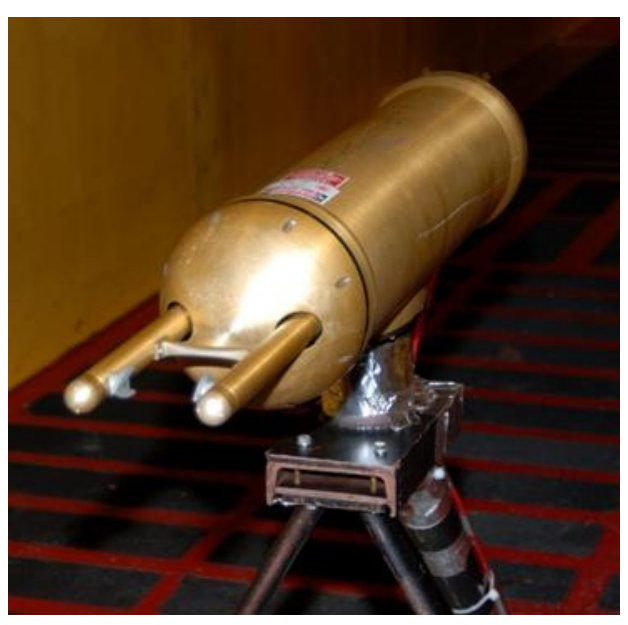

Optical Array Probe (OAP) $(15-450 \mu \mathrm{m})$

(Diode Shadowing)
Number Density for Mod1, Pair=15, DelP=30

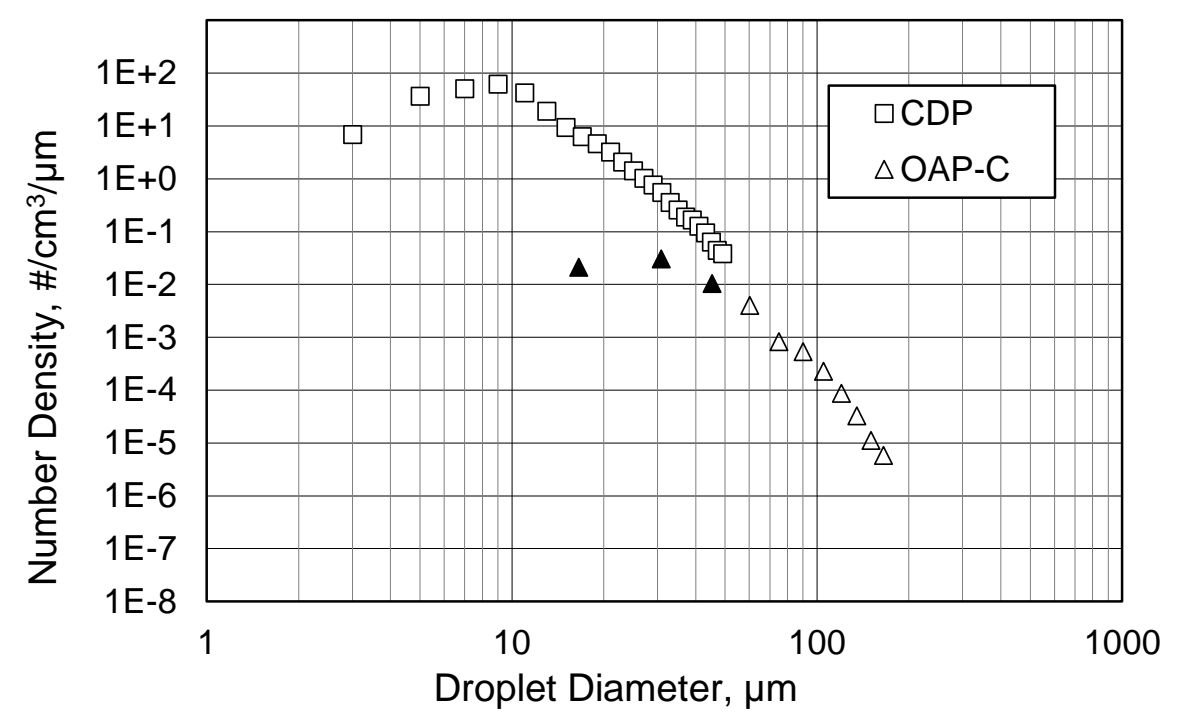

Normalized Cumulative Volume for Mod1,

Pair=15, DelP=30

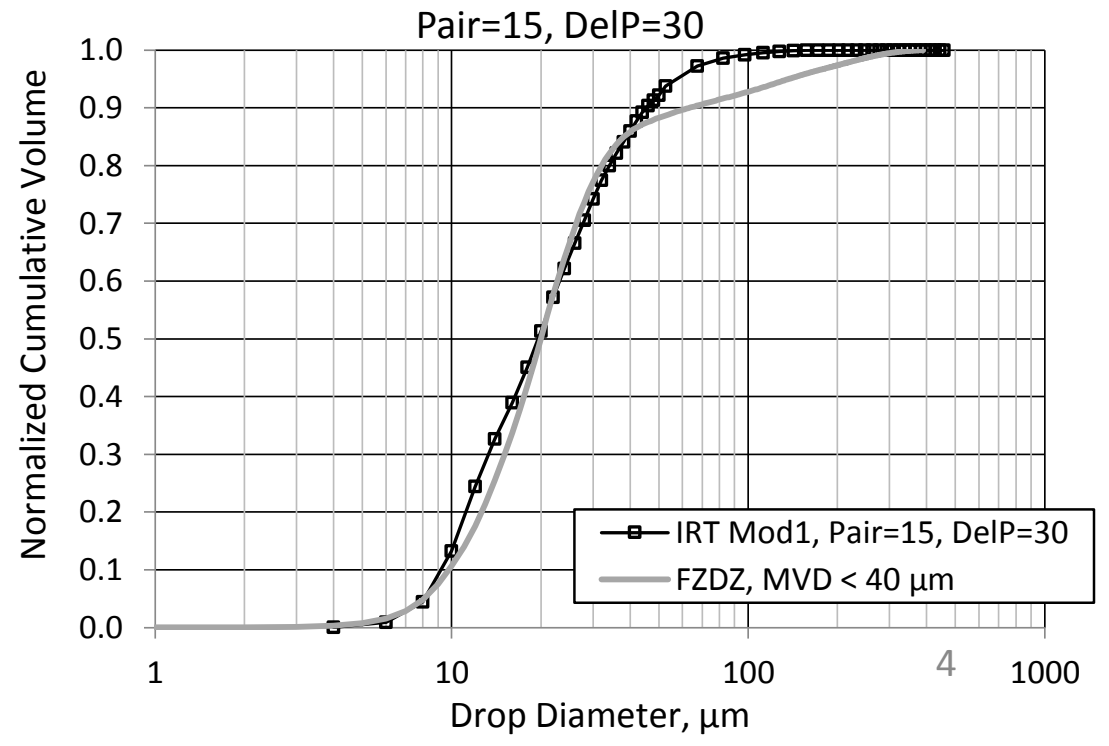




\section{IRT Drop-Size Measurement Procedures}

IRT Spraybars (viewed from upstream)

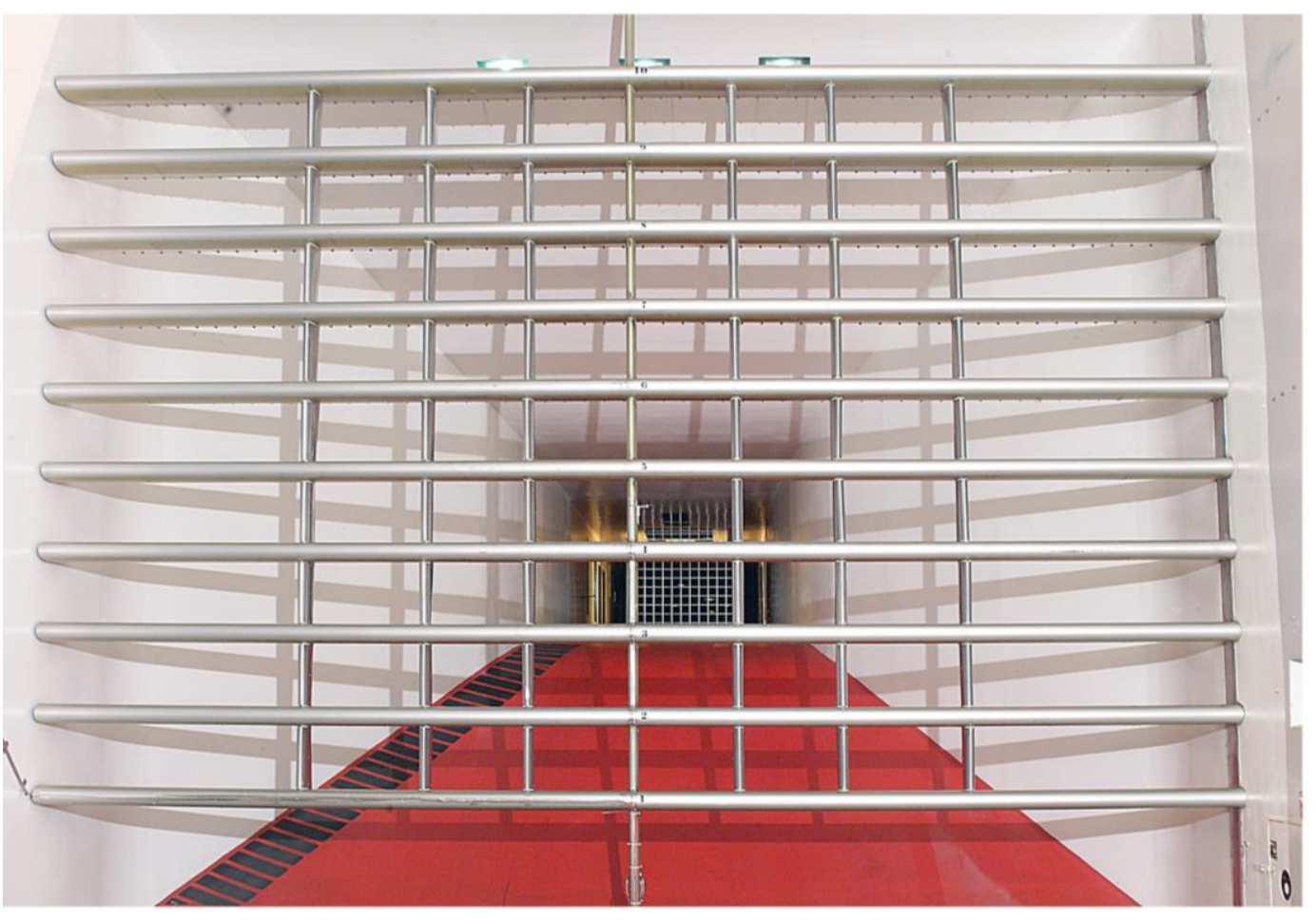

- Drop-size measurements are typically made with only the even- or odd-numbered spraybars

- This reduces number density, which in turn reduces the chances of coincidence error from the probes.

- It is also helpful in testing because spraying less water means the probe is more likely to remain free of ice.

- This is done ONLY for characterizing particle size distribution measurements. A study is done at each full calibration to determine which set of bars are best. 


\section{Creating Bimodal Distributions, Analytically}

- Superimpose two drop-size distributions (one from Mod1 nozzles, one from Standard nozzles):

- add the two liquid water contents values for each bin size

- IRT spraybars have only one air manifold, so both conditions must have the same air pressure.

- Calculate the new total volume

- Normalize LWC in each bin by the new total water content

- Calculate the Normalized Cumulative Volume. Plot against drop size.

- The "stark" bimodal (right) is the most distinctly bimodal distribution that can currently be created.

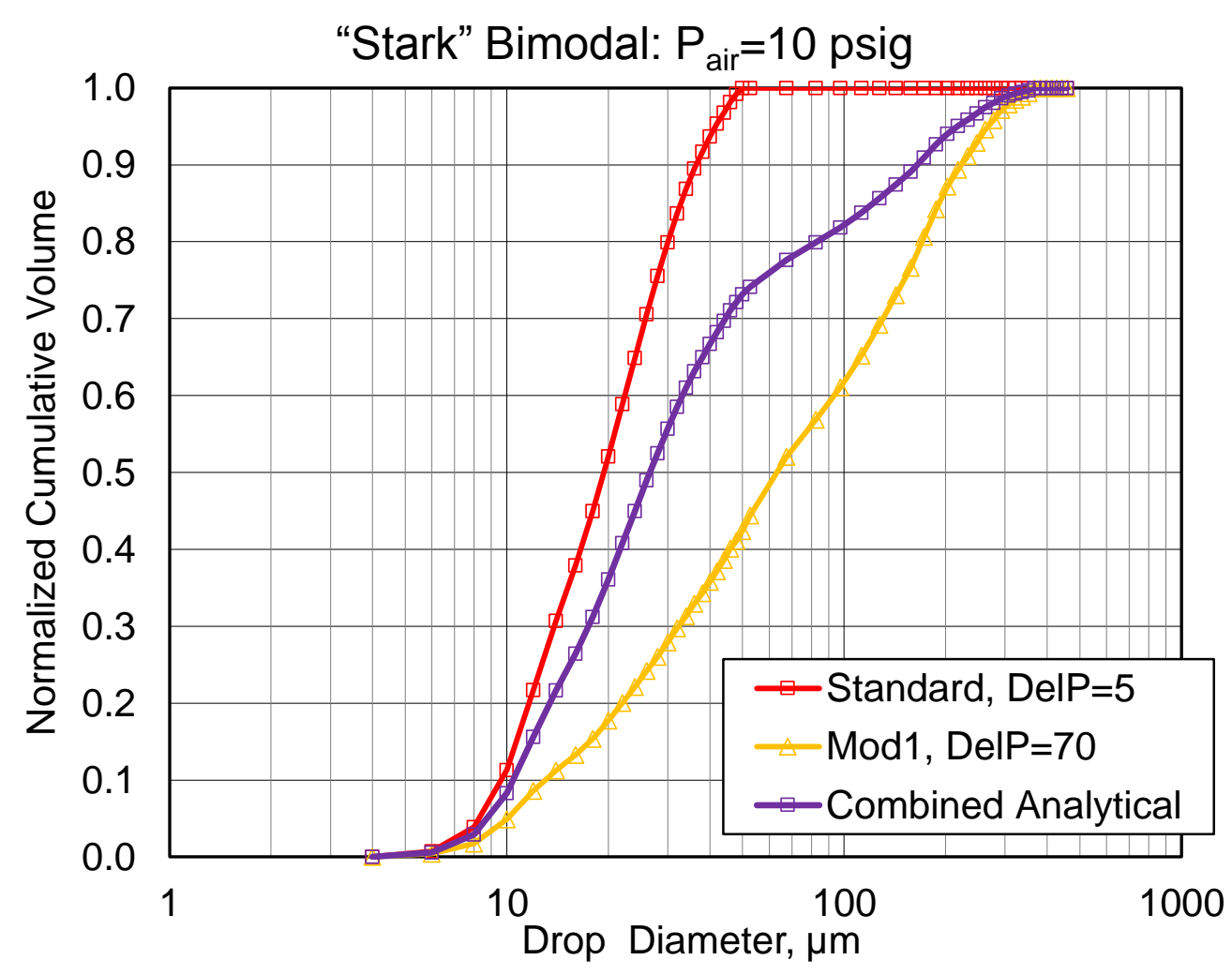




\section{Matching to FZDZ, MVD<40 $\mu \mathrm{m}$}

- We chose from the available IRT measured drop size distributions taken during the cloud calibration

- Requirements: air pressures must match, nozzle types must be different

- Optimized to a condition that was within $10 \%$ and matched better to the top $10 \%$ of the normalized cumulative LWC

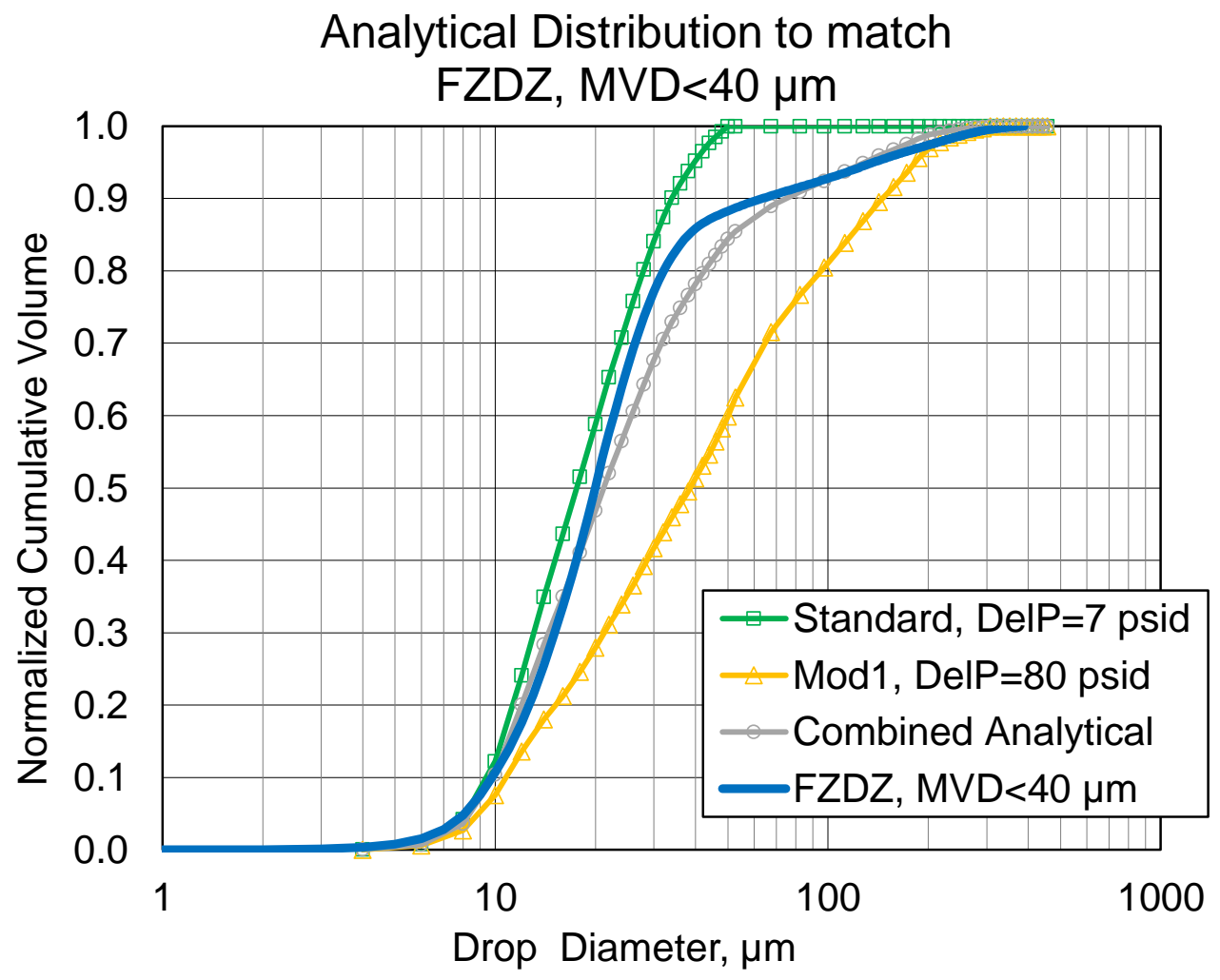




\section{Test Goals}

- Measured 4 spray conditions for the FZDZ, MVD<40 $\mu \mathrm{m}$ "match" distribution, and 3 for the "stark" bimodal:

1. Mod1 nozzles only (mono-modal, even spraybars)

2. Standard nozzles only (mono-modal, even spraybars)

3. Mod1 \& Standard nozzles together (bimodal), even-numbered spraybars

4. Mod1 \& Standard nozzles together (bimodal), all spraybars

- Compare the simultaneous-spray bimodal to the FZDZ, MVD<40 $\mu \mathrm{m}$ distribution

- Combine the measurements of the two individual sprays and compare the analytical superposition to the measured Mod1 \& Standard simultaneous spray

- Compare the even-numbered spraybars to all-spraybars 


\section{Results: "Stark" Bimodal}

- Compared the analytical "Stark" Bimodal: $\mathrm{P}_{\text {air }}=10$ psig sum of the two individual sprays to the distribution measured when everything was sprayed at once

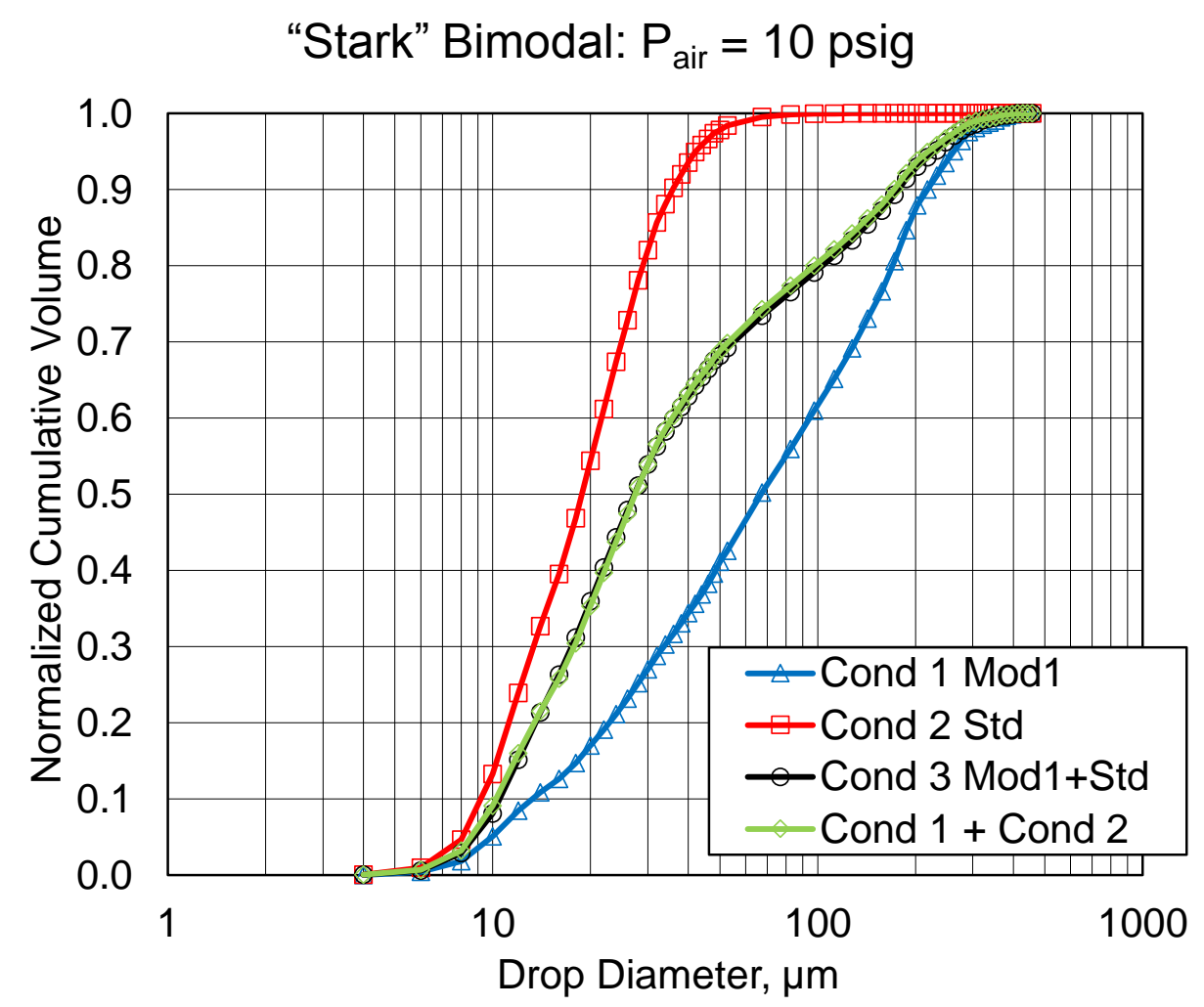

\begin{tabular}{|c|c|c|c|c|c|}
\hline \multicolumn{3}{|c|}{ Compared Distributions } & $\begin{array}{l}\text { Mean } \\
\text { Diff. }\end{array}$ & $\begin{array}{l}\text { Max } \\
\text { Diff. }\end{array}$ & $\begin{array}{l}\text { Diam. at } \\
\text { Max Diff }\end{array}$ \\
\hline Pair $=10$, sum of Mod 1 and Std & vs & Pair $=10$, Mod1+Std expt, even bars & $0.3 \%$ & $1.0 \%$ & $10 \mu \mathrm{m}$ \\
\hline
\end{tabular}




\section{Results: FZDZ, MVD<40 $\mu \mathrm{m}$ case}

- Compared the analytical sum of the two individual sprays to the distribution measured when everything was sprayed at once

- Also compared spraying even-numbered bars with spraying all bars

- Comparisons were good in both cases

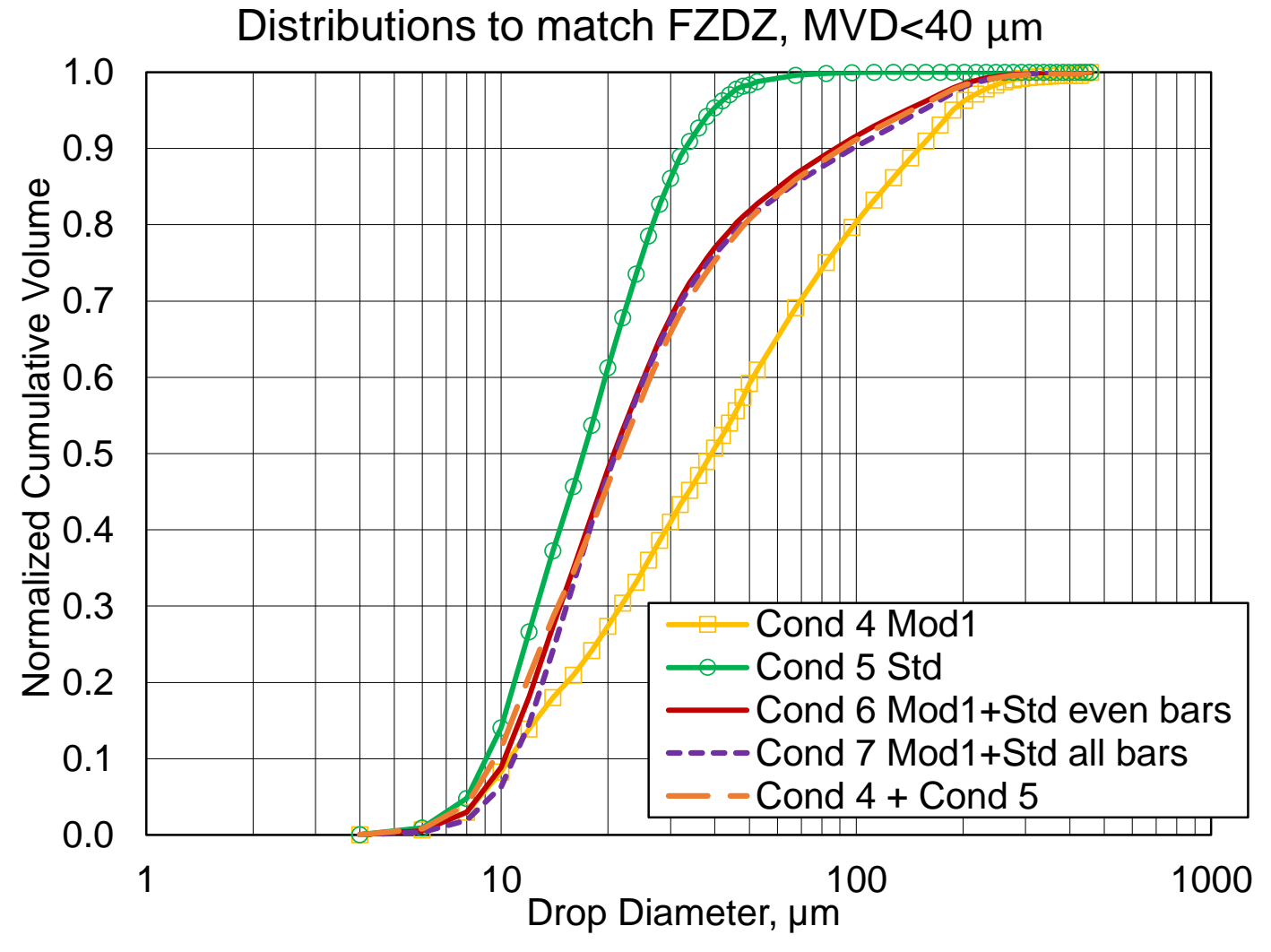

\begin{tabular}{|c|c|c|c|c|c|}
\hline \multicolumn{3}{|c|}{ Compared Distributions } & $\begin{array}{l}\text { Mean } \\
\text { Diff. }\end{array}$ & $\begin{array}{l}\text { Max } \\
\text { Diff. }\end{array}$ & $\begin{array}{l}\text { Diam. at } \\
\text { Max Diff. }\end{array}$ \\
\hline Pair $=15$, sum of Mod1 and Std & vs & Pair $=15$, Mod1+Std expt, even bars & $0.6 \%$ & $2.2 \%$ & $26 \mu \mathrm{m}$ \\
\hline Pair $=15$, Mod1+Std, expt., all bars & vs & Pair $=15$, Mod1+Std expt, even bars & $0.7 \%$ & $3.5 \%$ & $12 \mu \mathrm{m}$ \\
\hline
\end{tabular}




\section{Results: Created condition compared to App O FZDZ, MVD<40 $\mu \mathrm{m}$}

- Compared the distribution measured when everything was sprayed at once to the App O FZDZ $M V D<40 \mu m$

- Distributions matched within $10 \%$

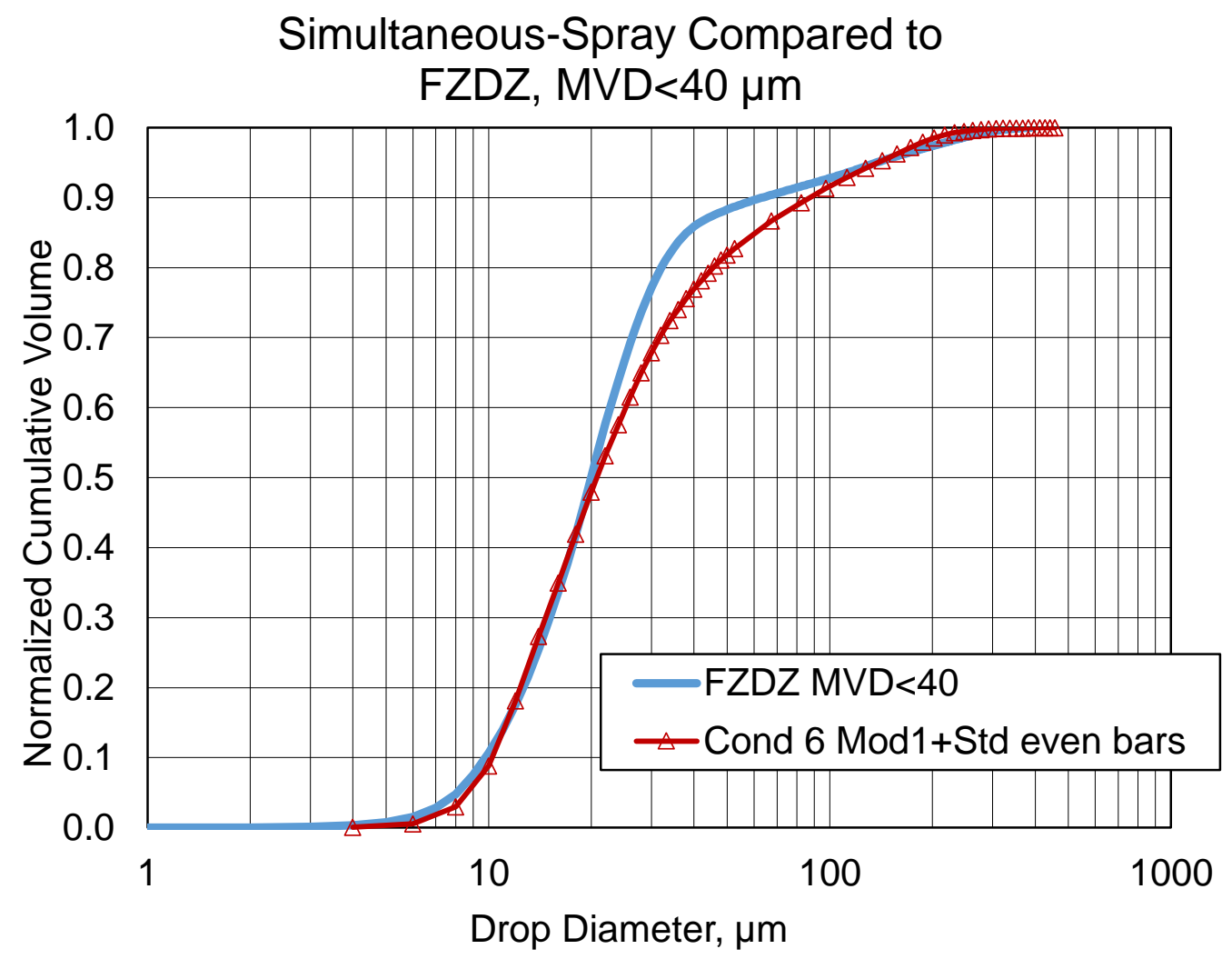

\begin{tabular}{|c|c|c|c|c|c|}
\hline \multicolumn{3}{|c|}{ Compared Distributions } & $\begin{array}{l}\text { Mean } \\
\text { Diff }\end{array}$ & $\begin{array}{l}\text { Max } \\
\text { Diff. }\end{array}$ & $\begin{array}{l}\text { Diam. at } \\
\text { Max Diff }\end{array}$ \\
\hline App. O., FZDZ, MVD<40 $\mu \mathrm{m}$ & vs & Pair $=15$, Mod1+Std expt, even bars & $2.7 \%$ & $9.6 \%$ & $36 \mu \mathrm{m}$ \\
\hline
\end{tabular}




\section{Further}

Drop-Size Distributions resembling

FZDZ, MVD<40 $\mu \mathrm{m}$

\section{comparison}

- Now Comparing MVD, Number Density, and Dv0.95

- Slope of curve is shallow in the upper region, so comparing Dv0.95 is tricky

- Number Density is reflective of number \& type of nozzles spraying

\begin{tabular}{|l|c|c|c|}
\hline \multicolumn{1}{|c|}{ Distribution Name } & $\begin{array}{c}\text { MVD } \\
(\mu \mathrm{m})\end{array}$ & $\begin{array}{c}\text { Dv0.95 } \\
(\mu \mathrm{m})\end{array}$ & $\begin{array}{c}\text { Number } \\
\text { Density } \\
\left(\# / \mathrm{cm}^{3}\right)\end{array}$ \\
\hline $\mathrm{P}_{\text {air }}=15$, Mod1 nozzles only (mono-modal) & 19.3 & 58.0 & 492 \\
\hline $\mathrm{P}_{\text {air }}=15$, Mod1+Std expt, even bars & 20.8 & 138.4 & 1692 \\
\hline $\mathrm{P}_{\text {air }}=15$, Mod1+Std expt, all bars & 21.0 & 153.8 & 2671 \\
\hline $\mathrm{P}_{\text {air }}=15$, sum of Mod1 and Std & 21.6 & 143.2 & 1670 \\
\hline App. O., FZDZ, MVD<40 $\mu \mathrm{m}$ & 20.0 & 137.1 & -- \\
\hline
\end{tabular}

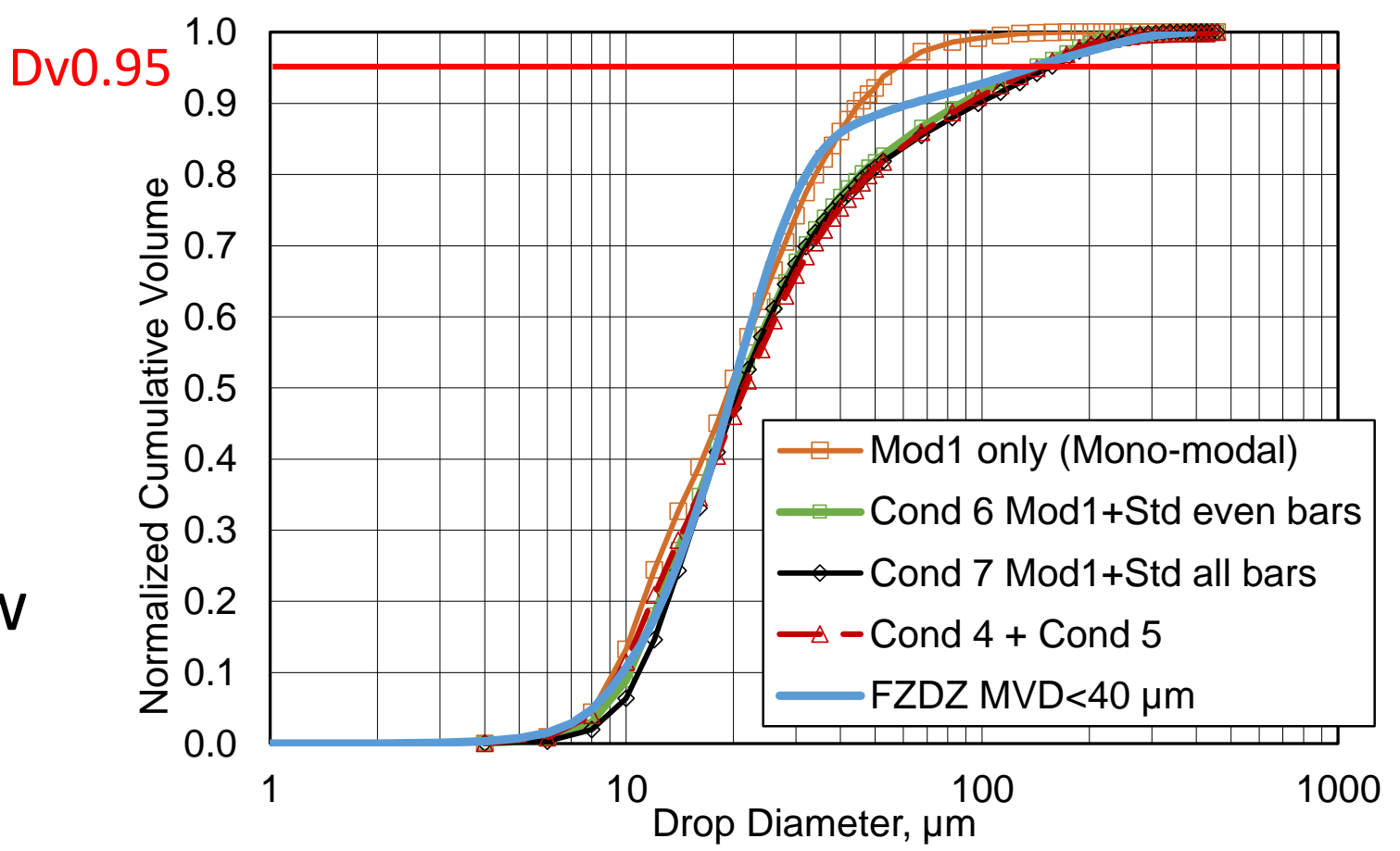




\section{Further Results: Cloud Uniformity}

100 knots

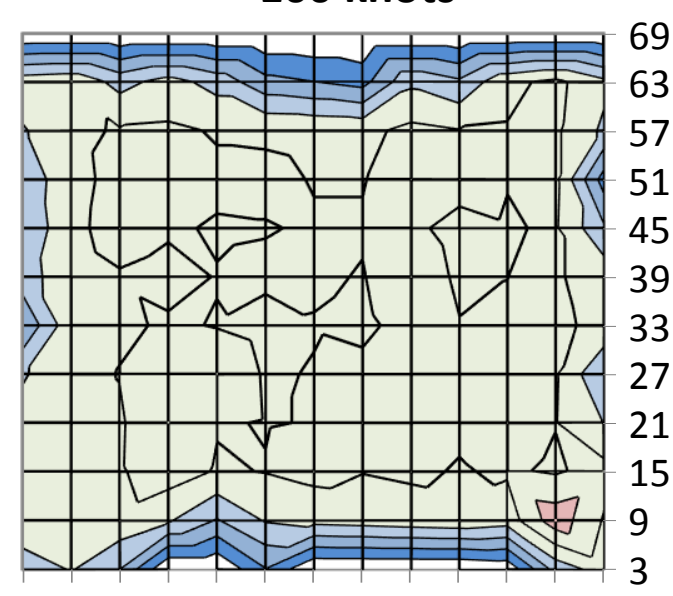

$\begin{array}{lllllll}-36 & -24 & -12 & 0 & 12 & 24 & 36\end{array}$

Distance from Centerline, in.
150 knots

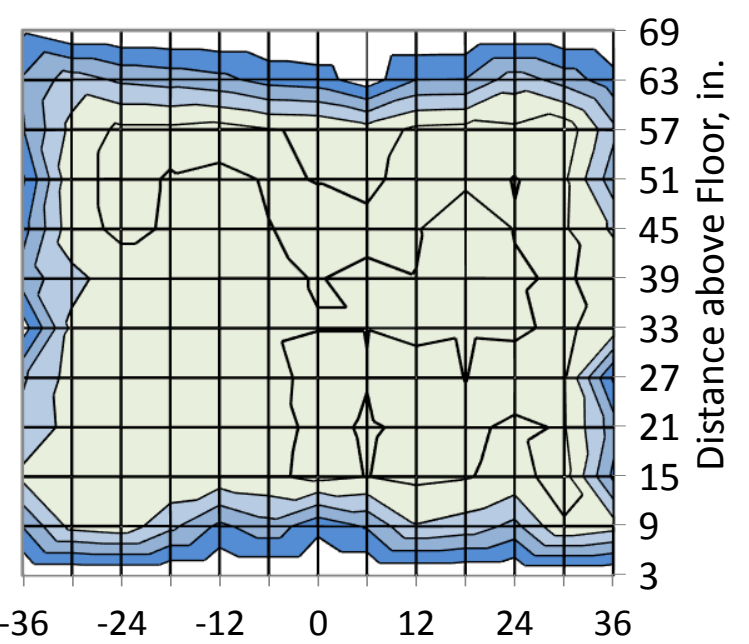

Distance from Centerline, in.

$\square$ 0.90-1.00 $\square$ 1.00-1.10 $\square$ 1.10-1.20 $\square$ 1.20-1.30

250 knots

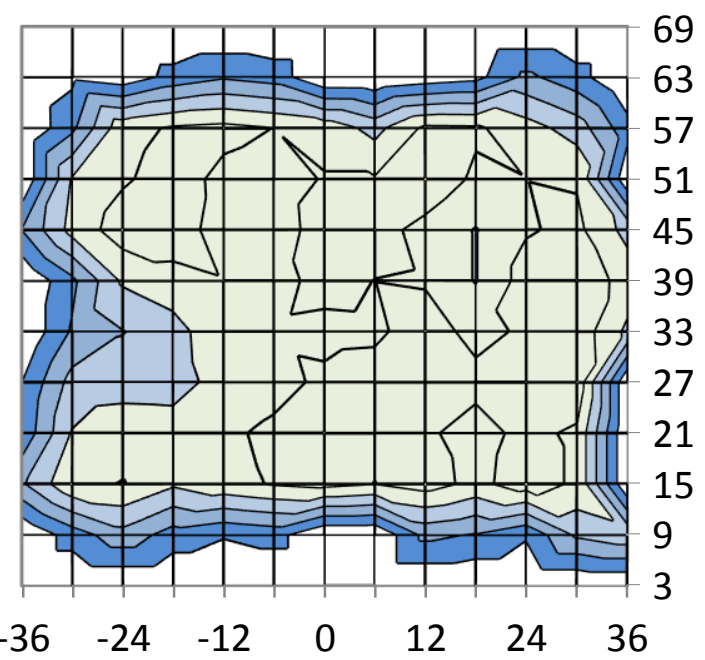

Distance from Centerline, in.

- Used the IRT's $6 \mathrm{ft} \times 6 \mathrm{ft}$ icing grid to measure cloud uniformity of the FZDZ, $\mathrm{MVD}<40 \mu \mathrm{m}$ match at three airspeeds

- Plots show the local LWC ratioed to the average of the center 12 elements

- Cloud uniformity is excellent for all three cases: $\pm 10 \%$

- Likely because over half the volume is contributed by the Standard nozzles, which typically have excellent cloud uniformity 


\section{Conclusions}

- The IRT can create a drop-size distribution that matches Appendix O FZDZ, MVD<40 $\mu \mathrm{m}$ within 10\%

- Combining conditions analytically has been proven to compare well with spraying them simultaneously. This suggests that we are not getting drop coalescence, and we can perform similar analyses to predict other bimodal distributions in the IRT.

- Spraying only the even-numbered bars gives a distribution much like spraying all bars.

- Cloud uniformity (at least LWC) for this condition is excellent. 


\section{Further Considerations:}

- Liquid Water Content for this condition is much too high: at an airspeed of 250 knots it is $1.45 \mathrm{~g} / \mathrm{m}^{3}$, instead of the desired $0.29-0.44 \mathrm{~g} / \mathrm{m}^{3}$.

- This means that model testing with this drop-size distribution will need to use scaling methods to match the freezing fraction.

- The primary interest is in the effect this drop-size distribution has on an ice shape or ice protection system.

- This work has been started and progress thus far will be described in the next talk

- There are still many parameters of SLD conditions that remain to be met. This presentation addresses the IRT's current attempts to understand the effect of bimodality. 


\section{Questions?}
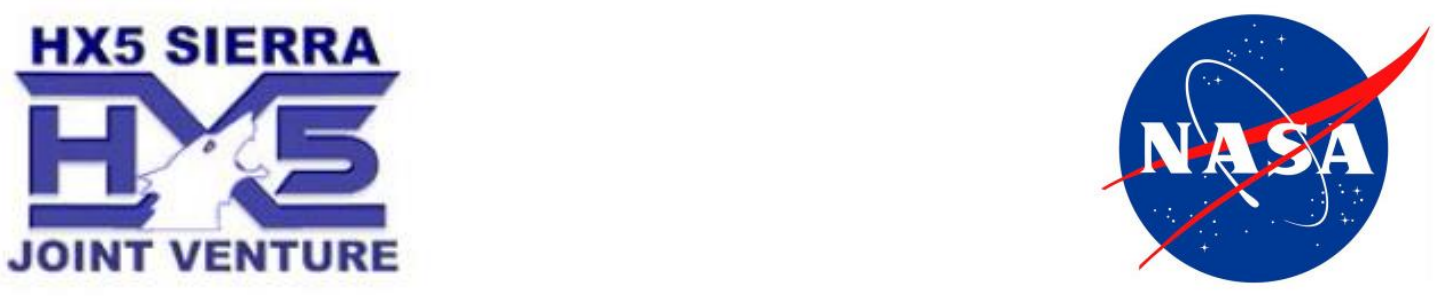